\title{
Structural and Functional Complexity of the Genomic Region Controlling AK-Toxin Biosynthesis and Pathogenicity in the Japanese Pear Pathotype of Alternaria alternata
}

\author{
Aiko Tanaka and Takashi Tsuge \\ Graduate School of Bioagricultural Sciences, Nagoya University, Chikusa, Nagoya 464-8601, Japan \\ Accepted 8 May 2000.
}

\begin{abstract}
The Japanese pear pathotype of Alternaria alternata produces host-specific AK-toxin and causes black spot of Japanese pear. Previously, a cosmid clone, pcAKT-1, was isolated that contains two genes, $A K T 1$ and $A K T 2$, within a 5.0-kb region required for AK-toxin biosynthesis. The wild-type strain has multiple, nonfunctional copies of these genes. In the present study, two additional genes, $A K T R-1$ and $A K T 3-1$, downstream of $A K T 2$ were identified. Transformation of the wild type with $A K T R-1$ - and AKT3-1-targeting vectors produced toxin-deficient $\left(\mathrm{Tox}^{-}\right)$, nonpathogenic mutants. DNA gel blot analysis, however, demonstrated that the fragments targeted in Tox ${ }^{-}$mutants were different from those containing $A K T R-1$ and $A K T 3-1$ on the transforming vectors. A cosmid clone, pcAKT-2, containing the targeted DNA was isolated and shown to carry two genes, $A K T R-2$ and $A K T 3-2$, with high similarity to $A K T R-1$ and $A K T 3-1$, respectively. Transcripts from not only $A K T R-2$ and $A K T 3-2$ but also $A K T R-1$ and $A K T 3-1$ were found in the wild type. DNA gel blot analysis with pulsed-field gel electrophoresis showed that $A K T 1, A K T 2$, $A K T 3$, and $A K T R$ and their homologues are on a single chromosome. These results indicate the structural and functional complexity of the genomic region controlling AK-toxin biosynthesis.
\end{abstract}

The imperfect fungus Alternaria alternata is one of the most cosmopolitan fungal species and is generally saprophytic (Rotem 1994). This species, however, contains seven pathogens that cause severe disease on different plants due to production of toxins effective only against the host plants (Nishimura and Kohmoto 1983; Kohmoto et al. 1995). These A. alternata host-specific forms have been designated as pathotypes (Nishimura 1980; Nishimura and Kohmoto 1983; Kohmoto et al. 1995). The toxins are low-molecular-weight metabolites of diverse structure, and their participation in es-

Corresponding author: Takashi Tsuge

E-mail: ttsuge@agr.nagoya-u.ac.jp

Nucleotide and/or amino acid sequence data for AKTR-1, AKT3-1, $A K T R-2$, and $A K T 3-2$ are to be found in the DDBJ, GenBank, and EMBL data bases as accession numbers AB035491, AB035492, AB035493, and AB035494, respectively. tablishment of plant disease is one of the most clearly understood mechanisms of host-selective pathogenesis (Yoder 1980; Nishimura and Kohmoto 1983; Scheffer and Livingston 1984; Walton 1996). A. alternata pathotypes are a fascinating case for studying intraspecific variation and evolution of pathogenicity in plant-pathogenic fungi.

The Japanese pear pathotype of A. alternata produces AKtoxin and causes black spot of certain cultivars of Japanese pear, including the commercially important cultivar Nijisseiki (Tanaka 1933; Nakashima et al. 1985; Otani et al. 1985). This disease first became prominent in the early 1900s, shortly after cultivation of Nijisseiki pear was initiated, and has been the most critical problem in pear cultivation since (Tanaka 1933; Nishimura and Kohmoto 1983).

Recently, we isolated AK-toxin-deficient $\left(\mathrm{Tox}^{-}\right)$mutants of A. alternata by restriction enzyme-mediated integration (REMI) mutagenesis and cloned the genes for toxin biosynthesis from a tagged Tox $^{-}$mutant by recovery of genomic DNA flanking the tag (Tanaka et al. 1999). Structural and functional analyses of this DNA revealed two genes, designated $A K T 1$ and $A K T 2$ (Tanaka et al. 1999). AKT1 encodes a carboxyl-activating enzymes homologue, and $A K T 2$ encodes a protein of unknown function (Tanaka et al. 1999). Their essential roles in toxin biosynthesis and in pathogenicity were proven by targeted gene disruption, which caused complete loss of both abilities (Tanaka et al. 1999). DNA gel blot analysis of wild type and the $A K T 1$ or $A K T 2$ mutants demonstrated that the wild-type strain has additional copies of these genes, which are nonfunctional in toxin production (Tanaka et al. 1999).

DNA gel blot analysis revealed that $A K T 1$ and $A K T 2$ are unique to three A. alternata pathotypes: Japanese pear, strawberry, and tangerine (Tanaka et al. 1999; Masunaka et al. 2000). The strawberry pathotype produces AF-toxin and causes Alternaria black spot of strawberry (Maekawa et al. 1984; Nakatsuka et al. 1986). The tangerine pathotype produces ACT-toxin and causes brown spot of tangerines and mandarins, a disease that has not occurred in Japan so far (Pegg 1966; Kohmoto et al. 1993). Toxins of these three pathotypes have a common 9,10-epoxy-8-hydroxy-9-methyl-decatrienoic acid structural moiety (Nakashima et al. 1985; Nakatsuka et al. 1986; Kohmoto et al. 1993), a precursor of all these toxins (Feng et al. 1990; Nakatsuka et al. 1990). Thus, we hypothesized that the genes encode the enzymes for biosynthesis of this 
common precursor. The $A K T 1$ - or $A K T 2$-targeted mutants fail to produce AK-toxin and this precursor (Tanaka et al. 1999).

There is increasing evidence that genes for secondary metabolites are clustered in fungi (Keller and Hohn 1997). We determined previously that $A K T 1$ and $A K T 2$ are located within a 5.0-kb region (Tanaka et al. 1999). In this study, we describe two additional open reading frames (ORFR and ORF3) downstream of $A K T 2$ that are present in multiple copies. When particular versions of these ORFs are disrupted, Tox ${ }^{-}$mutants result. As with $A K T 1$ and $A K T 2$, we determined the presence of additional, nonfunctional copies of these ORFs in wild type and identified the functional copies for toxin biosynthesis. Thus, it appears that the locus encoding ability to produce AK-toxin is structurally and functionally complex: multiple, non-identical copies of the genes are present; however, only one of each is functional.

\section{RESULTS}

Identification of two ORFs downstream of the AKT2 gene.

The nucleotide sequence of a 7.0-kb region downstream of $A K T 2$ was analyzed, and two ORFs (ORFR and ORF3) identified (Fig. 1).

ORFR (1,332 bp) is a single exon encoding a 444 amino acid protein with two recognizable domains: a zinc binuclear cluster DNA-binding domain $\left(\mathrm{CX}_{2} \mathrm{CX}_{6} \mathrm{CX}_{6} \mathrm{CX}_{2} \mathrm{CX}_{6} \mathrm{C}\right)$ in the amino terminal region and an internal leucine zipper domain $\left(\mathrm{LX}_{6} \mathrm{LX}_{6} \mathrm{LX}_{6} \mathrm{~L}\right)$ (Fig. 2). Proteins with the zinc binuclear cluster DNA-binding domain are known to be typical regulatory factors in fungi and have been placed in a single protein family, designated Zn(II)2Cys6 (Todd and Andrianopoulos 1997). The highest similarity is to the $a f l R$-encoding proteins of Aspergillus species, which are positive regulators required for expression of other pathway genes for biosynthesis of aflatoxin and its derivatives (Woloshuk et al. 1994; Yu et al. 1996) (Fig. 2). The zinc binuclear cluster domain of the ORFR product has similarity also to those of Pip2 (Rottensteiner et al. 1996) and Gal4 (Laughon and Gesteland 1984) of Saccharomyces cerevisiae, the type proteins for this family.

ORF3 (888 bp) encodes a protein of 296 amino acids after splicing of three putative introns (Fig. 1). Introns were deduced on the basis of presence of consensus sequences for
B

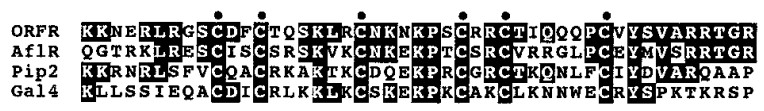

Fig. 2. Similarity of the open reading frame (ORF) ORFR-encoded protein to other proteins. A, Amino acid sequence encoded by ORFR. Zinc binuclear DNA-binding domain in amino terminal region and internal leucine zipper domain are underlined. Dots above sequences indicate highly conserved cysteines and leucines in these domains. B, Amino acid sequence alignment of zinc binuclear cluster domain of ORFRencoded protein with those of AflR of Aspergillus nidulans (Yu et al. 1996) and Pip2 (Rottensteiner et al. 1996) and Gal4 (Laughon and Gesteland 1984) of Saccharomyces cerevisiae. Amino acids conserved between the ORFR product and any of the others are indicated as white letters on a black background. Dots above sequence indicate highly conserved cysteines in this domain.
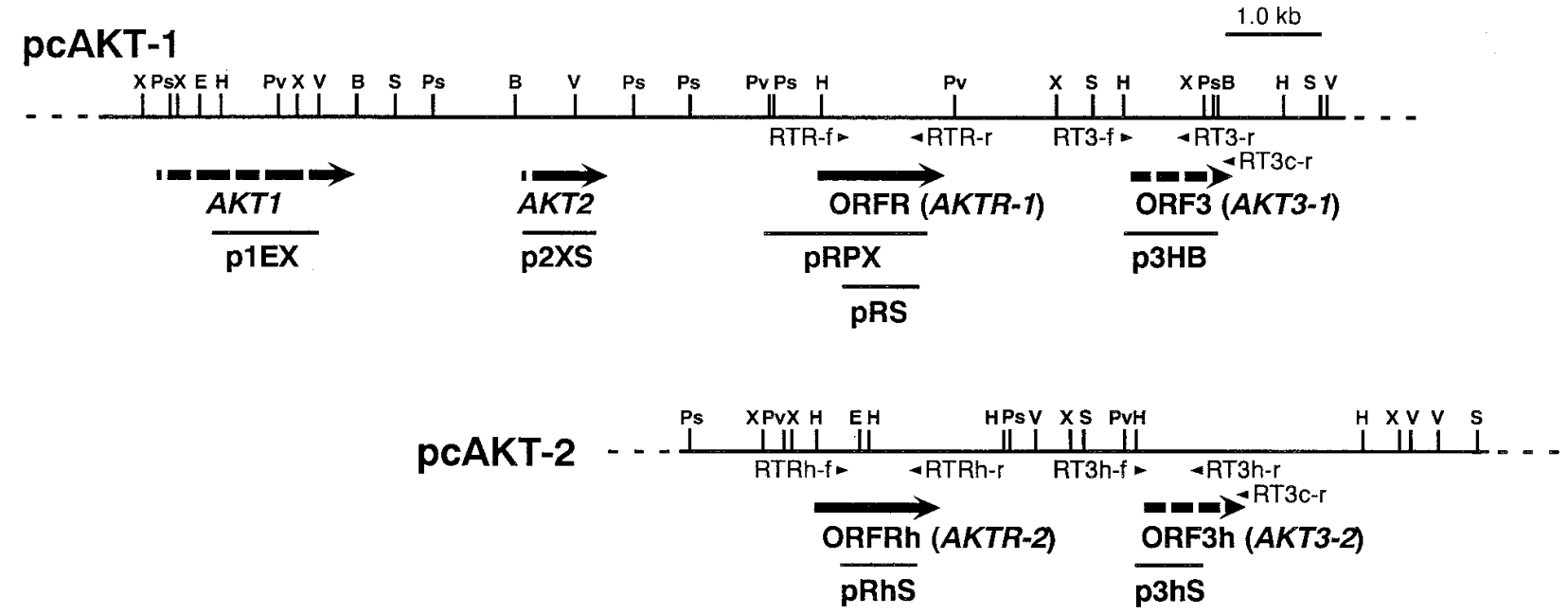

Fig. 1. Partial structure of cosmid clones pcAKT-1 and pcAKT-2. These clones were isolated from a genomic cosmid library of the wild-type strain $15 \mathrm{~A}$. The $A K T 1$ and $A K T 2$ genes are essential for AK-toxin biosynthesis (Tanaka et al. 1999). Open reading frames (ORFs) ORFR (AKTR-1) and ORF3 $(A K T 3-1)$ in pcAKT-1 and ORFRh $(A K T R-2)$ and ORF3h $(A K T 3-2)$ in pcAKT-2 were identified in this study. Arrows indicate protein coding regions; white segments indicate positions of introns. Arrowheads above ORFs denote orientation and location of oligonucleotide primers used in polymerase chain reaction (PCR) and reverse transcription-PCR experiments. p1EX, p2XS, pRPX, pRS, pRhS, p3HB, and p3hS were made by cloning indicated fragments in pBluescript KS+ or pGEM-T Easy, and used as probes for hybridization experiments. Abbreviations: B, BamHI; H, HindIII; E, EcoRI; Ps, PstI; Pv, PvuII; S, SphI; V, EcoRV; X, XhoI. 
$5^{\prime}$ splice sites $[\mathrm{GT}(\mathrm{A} / \mathrm{G} / \mathrm{T})(\mathrm{A} / \mathrm{C} / \mathrm{T}) \mathrm{G}(\mathrm{T} / \mathrm{C})]$ and $3^{\prime}$ splice sites [(C/T)AG] typical of fungal genes (Bruchez et al. 1993). A BLAST data base search revealed that the putative ORF3encoded protein has similarity to members of the hydratase/ isomerase enzyme family, such as enoyl-CoA hydratases, crotonases, naphthoate synthases, and 4-chlorobenzoyl-CoA dehalogenases (Müller-Newen and Stoffel 1993) (Fig. 3). The ORF3 product reveals the highest similarity ( 28.6 and $24.8 \%$ identities, respectively) to enoyl-CoA hydratase of Rhodobacter capsulatus, which is involved in $\beta$-oxidation of fatty acids (Beckman and Kranz 1991), and crotonase of Thermoanaerobacterium thermosaccharolytium, which is involved in butanoate metabolism (GenBank accession no. CAB07495) (Fig. 3). The ORF3-encoded protein terminates with a peroxisomal targeting signal type 1 (PTS1) tripeptide PKL that conforms to the PTS1 consensus motif established for S. cerevisiae (Elgersma et al. 1996).

\section{Mutation of ORFR and ORF3 by gene targeting.}

To determine the function of ORFR in AK-toxin biosynthesis, homologous recombination was employed to replace ORFR with plasmid pGDTR, which contains the hygromycin B phosphotransferase gene $(h p h)$ flanked by $5^{\prime}$ and $3^{\prime}$ sequences from ORFR (Fig. 4A). For ORF3, pGDT3, which was constructed by inserting a 1.0-kb ORF3 fragment in a transformation vector containing $h p h$, was used for disruption (Fig. 5A). Transformation of the wild-type strain 15A with pGDTR and pGDT3 yielded eight out of 100 pGDTR transformants and six out of 100 pGDT3 transformants with complete loss of pathogenicity (Fig. 6). Culture filtrates of the wild type and all pathogenic transformants tested showed

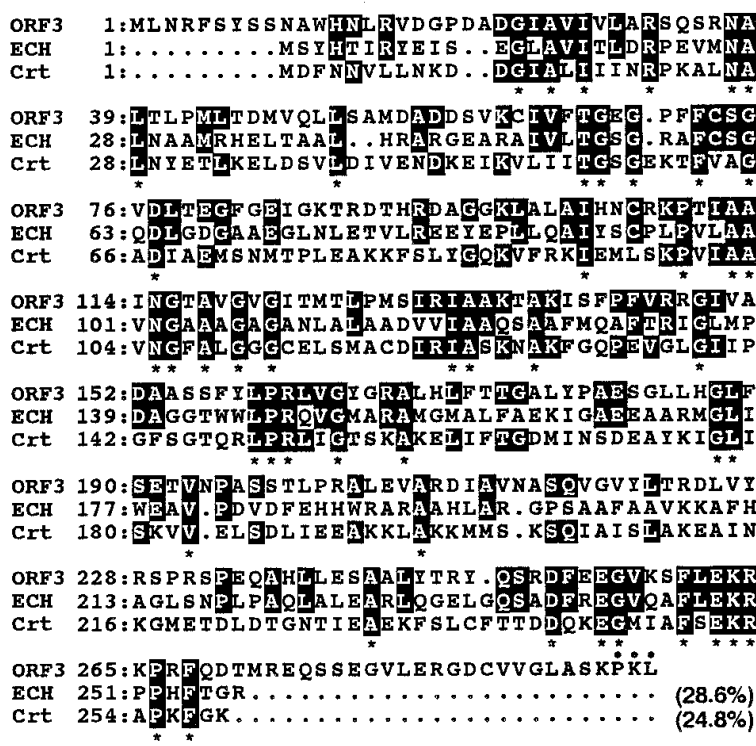

Fig. 3. Similarity of the open reading frame (ORF) ORF3-encoded protein to other proteins. Amino acid sequence of the ORF3-encoded protein was aligned with those of enoyl-CoA hydratase of Rhodobacter capsulatus (ECH) (Beckman and Kranz 1991) and crotonase of Thermoanaerobacterium thermosaccharolytium (Crt) (GenBank accession no. CAB07495). Amino acids conserved between the ORF3 product and any of the others are indicated as white letters on a black background. Amino acids identical in all sequences are indicated by asterisks. The peroxisomal targeting signal type 1-like tripeptide PKL at the carboxy terminus of the ORF3 product is shown with dots.

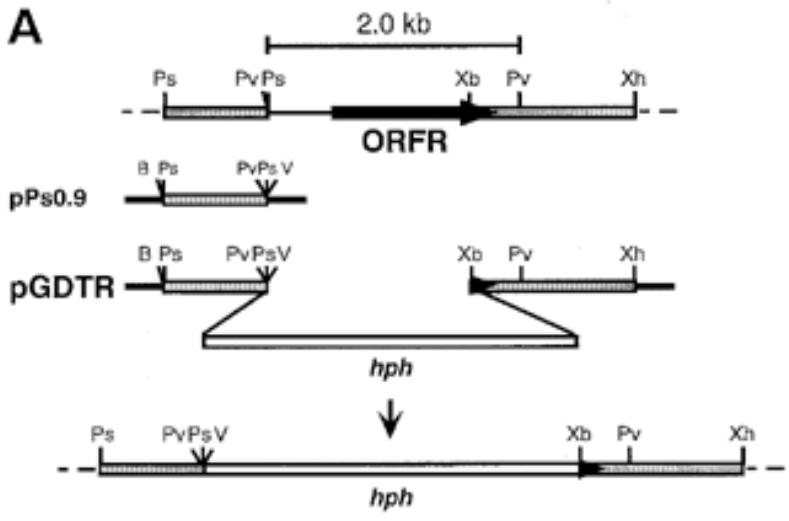

B
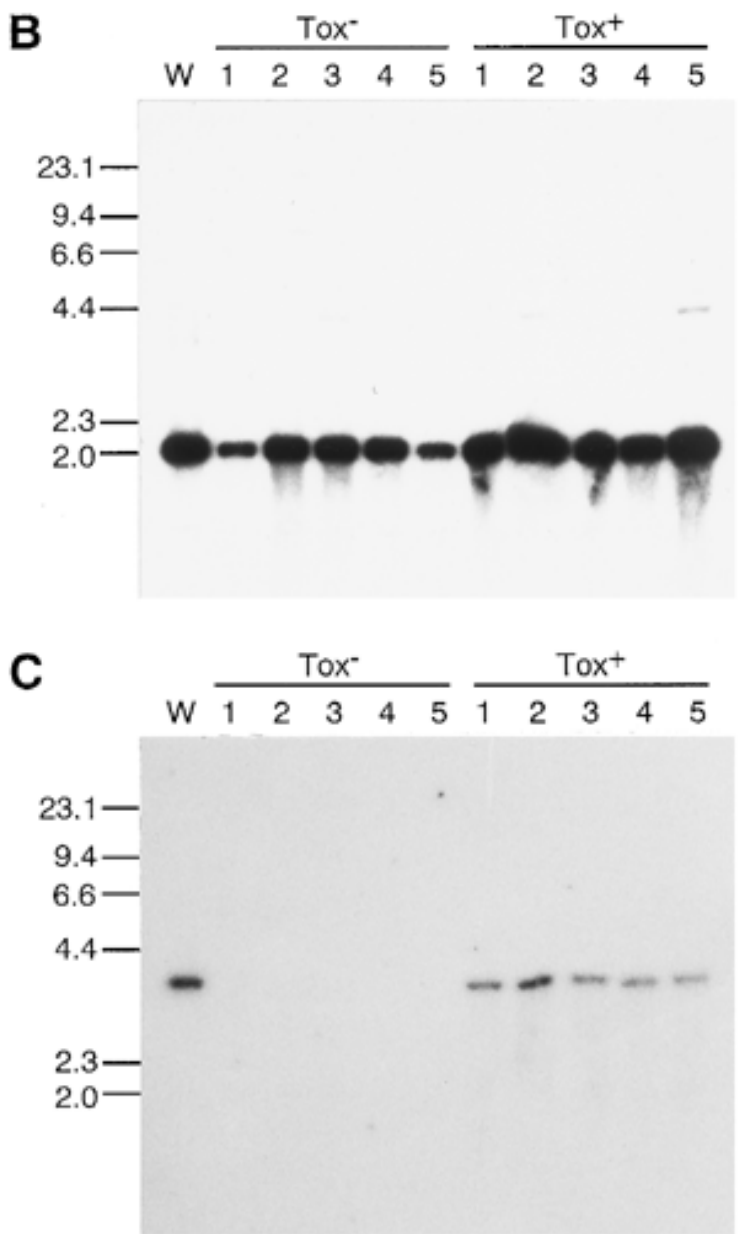

Fig. 4. Transformation-mediated targeting of the open reading frame (ORF) ORFR. A, Structure of ORFR before and after homologous integration of the ORFR-targeting vector pGDTR. pGDTR contains the hygromycin B phosphotransferase gene $(h p h)$ flanked by the $5^{\prime}$ sequence $(0.8 \mathrm{~kb})$ and $3^{\prime}$ sequence $(1.3 \mathrm{~kb})$ from ORFR in pSH75 (Kimura and Tsuge 1993). Abbreviations: B, BamHI; Ps, PstI; Pv, PvuII; V, EcoRV; $\mathrm{Xb}, \mathrm{XbaI}$; Xh, XhoI. B and C, DNA gel blot analysis of pGDTR transformants. Total DNA from the wild-type strain (W), Tox ${ }^{-}$transformants or Tox ${ }^{+}$transformants was digested with $P v u I I$ and fractionated in a $0.8 \%$ agarose gel. Blots were hybridized with the pRPX insert, which was replaced with the $h p h$ gene in pGDTR (see Figure 1). C, Blots of $\mathbf{B}$ were stripped of probe and rehybridized with the $\mathrm{pRhS}$ insert (see Figure 1). Sizes (in $\mathrm{kb}$ ) of marker DNA fragments (HindIII-digested $\lambda$ DNA) are indicated on left. 
toxicity to Nijisseiki pear leaves, but those of the nonpathogenic transformants had no toxicity (Fig. 6). High-performance liquid chromatography analysis also could not detect AK-toxin in culture filtrates of the nonpathogenic transformants, indicating loss of AK-toxin production.

The level of a precursor of AK-toxin, 9,10-epoxy-8hydroxy-9-methyl-decatrienoic acid (Feng et al. 1990; Nakatsuka et al. 1990), in culture filtrates of a subset of toxinproducing $\left(\mathrm{Tox}^{+}\right)$and toxin-deficient $\left(\mathrm{Tox}^{-}\right)$transformants was quantified by high-performance liquid chromatography. Culture filtrates of $\mathrm{Tox}^{+}$transformants contained the precursor molecule: 37 to $308 \mathrm{ng}$ per $\mathrm{ml}$ in five pGDTR transformants and 208 to $834 \mathrm{ng}$ per $\mathrm{ml}$ in five pGDT3 transformants. In contrast, 9,10-epoxy-8-hydroxy-9-methyl-decatrienoic acid could not be detected in culture filtrates of each of five Tox transformants obtained by transformation with pGDTR and pGDT3.

All Tox ${ }^{-}$transformants grew and sporulated as well as the wild-type strain (data not shown). There were no significant
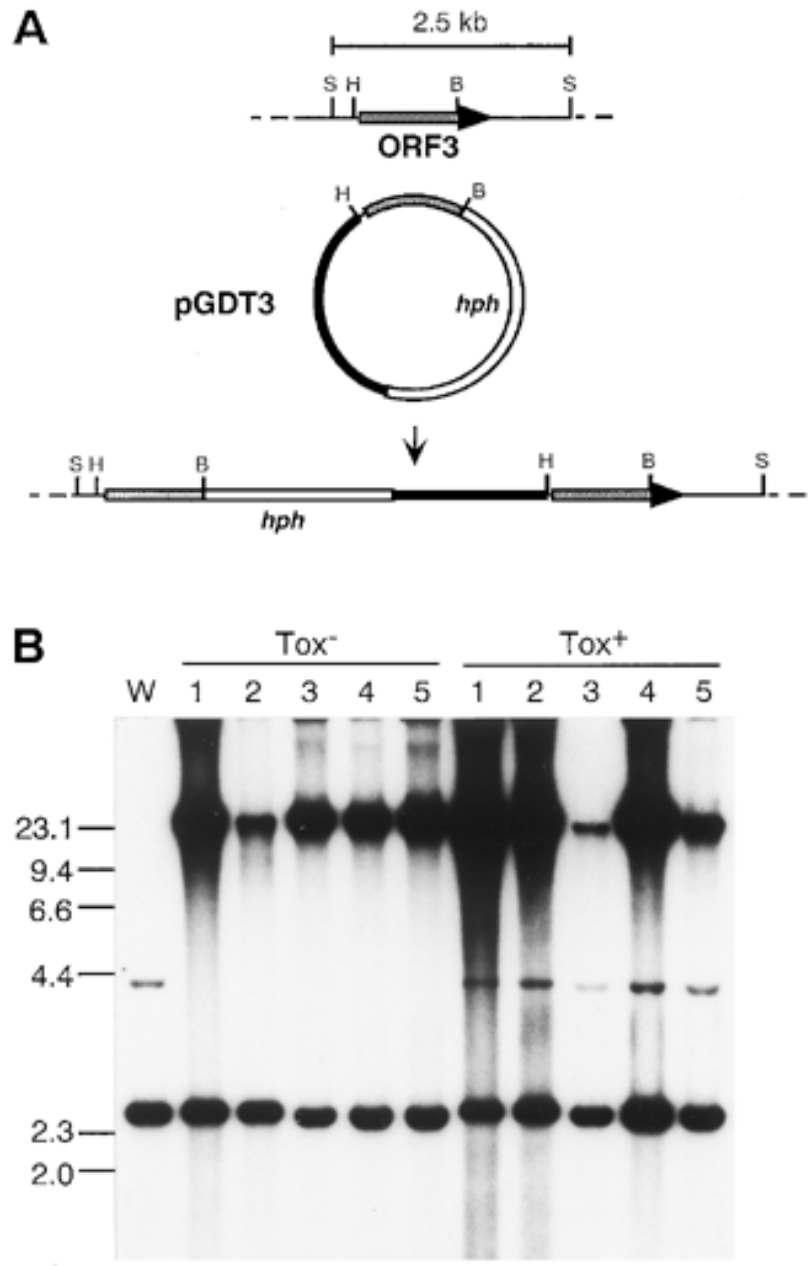

Fig. 5. Transformation-mediated targeting of the open reading frame (ORF) ORF3. A, Structure of ORF3 before and after homologous integration of the ORF3-targeting vector pGDT3. pGDT3 contains the 1.0-kb BamHI-HindIII fragment of ORF3 in pSH75 (Kimura and Tsuge 1993). Abbreviations: B, BamHI; S, SphI. B, DNA gel blot analysis of pGDT3 transformants. Total DNA from the wild-type strain (W), Tox ${ }^{-}$transformants or $\mathrm{Tox}^{+}$transformants was digested with $S p h \mathrm{I}$ and fractionated in a $0.8 \%$ agarose gel. Blots were probed with the pGDT3 insert. Sizes (in kb) of marker DNA fragments (HindIII-digested $\lambda$ DNA) are indicated on left. differences in spore germination, appressorium formation, or hyphal penetration on cellulose membranes between the wild type and each of these mutants (data not shown). These results suggest that loss of pathogenicity is attributable to loss of AKtoxin production.

The mode of integration of the vector in a subset of Tox and Tox ${ }^{-}$transformants was analyzed by DNA gel blot analysis (Figs. 4B and 5B). Total DNA of the wild type and pGDTR transformants was digested with $P v u I I$, and the blot probed with the pRPX insert, which was replaced with the $h p h$ gene in pGDTR (Figs. 1 and 4A). The probe hybridized to a $2.0-\mathrm{kb}$ fragment in not only wild type and $\mathrm{Tox}^{+}$transformants but also Tox ${ }^{-}$transformants (Fig. 4B). The 2.0-kb fragment corresponds to the $P v u \mathrm{II}$ fragment containing ORFR in pcAKT-1 (Figs. 1 and 4A), suggesting that ORFR had not been disrupted in the Tox ${ }^{-}$transformants.

Total DNA of pGDT3 transformants was digested with SphI, which has no site in pGDT3, and the blot was probed with the pGDT3 insert (Fig. 5A). The restriction map of pcAKT-1 predicts that the probe would hybridize to a $2.5-\mathrm{kb}$ SphI fragment in the wild type (Fig. 5A); however, two bands $(2.5$ and $4.0 \mathrm{~kb}$ ) hybridized (Fig. 5B). The 2.5-kb signal was more intense. Thus, the wild type has multiple copies of the ORF3 homologue. All $\mathrm{Tox}^{+}$transformants contained these two bands (Fig. 5B). All Tox transformants lacked the 4.0-kb band, implying that pGDT3 did not disrupt the genomic copy of ORF3, but did disrupt the 4.0-kb SphI copy (Fig. 5B). Tox ${ }^{+}$and Tox $^{-}$transformants both carried high-molecular-weight hybridizing bands $(>23 \mathrm{~kb})$, indicating integration of plasmids as tandem repeats (Fig. 5B). Such integration patterns are usual in transformation of $A$. alternata (Tsuge et al. 1990; Shiotani and Tsuge 1995; Tanaka et al. 1999).

\section{Isolation and characterization of ORFRh and ORF3h.}

DNA gel blot analysis of Tox ${ }^{-}$transformants demonstrated that genomic copies of ORFR and ORF3 cloned in pcAKT-1 had not been disrupted. To isolate the targeted actual genes, a cosmid genomic library of the wild-type strain was screened with an ORF3 probe (p3HB insert) (Fig. 1), and 30 positive clones selected. DNA of positive clones was digested with $S p h \mathrm{I}$ and hybridized with the same probe. Among 30 clones, 29 contained the $2.5-\mathrm{kb} S p h \mathrm{I}$ fragment hybridizing to the probe; the remaining one, which we have named pcAKT-2, contained the 4.0-kb SphI fragment (Fig. 1). This result strongly suggests that the wild-type strain has multiple copies of ORF3, and indicates that pcAKT-2 contains the copy, which was disrupted in Tox ${ }^{-}$pGDT3 transformants. Positive clones were also digested with $P v u \mathrm{II}$ and hybridized with the ORFR probe (pRPX insert) (Fig. 1). Unexpectedly, pcAKT-2 had a 3.6-kb $P v u I I$ fragment hybridizing to the probe, while the other clones had the $2.0-\mathrm{kb}$ fragment. The $3.6-\mathrm{kb}$ signal was weaker than the $2.0-\mathrm{kb}$ signal, suggesting that pcAKT- 2 contains an ORFR homologue.

Sequencing of the $6.5-\mathrm{kb}$ region of pcAKT-2 containing the ORFR and ORF3 homologues detected two putative protein coding regions, designated ORFRh and ORF3h (Fig. 1), which are highly similar to ORFR and ORF3. Figure 7 is a comparison of the $6.5-\mathrm{kb}$ regions of pcAKT-1 and pcAKT- 2 . ORFR (1,332 bp) and ORFRh (1,305 bp) are single exons, 84.8 and $74.1 \%$ identical in nucleotide and amino acid se- 
quences, respectively (Fig. 7A and B). The amino terminal regions (59 amino acids) have $98.3 \%$ identity, including the zinc binuclear cluster domain with only one amino acid residue difference (Fig. 7B). The carboxy terminal regions (59 amino acids) are also highly conserved (96.6\% identity) (Fig. 7B). However, the internal regions (326 and 317 amino acids in ORFR and ORFRh, respectively) containing the leucine zipper domain are only $65.6 \%$ identical (Fig. 7B). The vari-

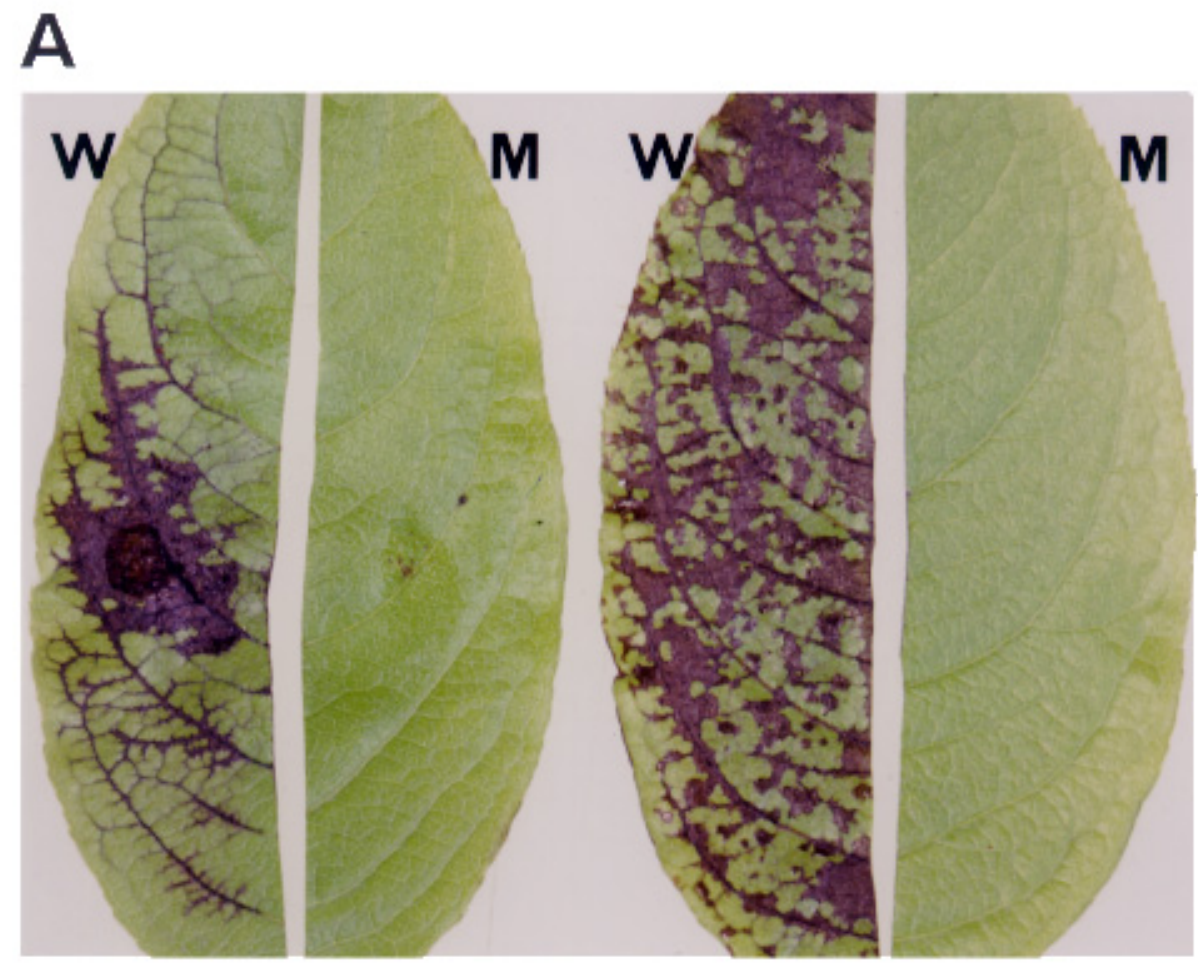

\section{B}
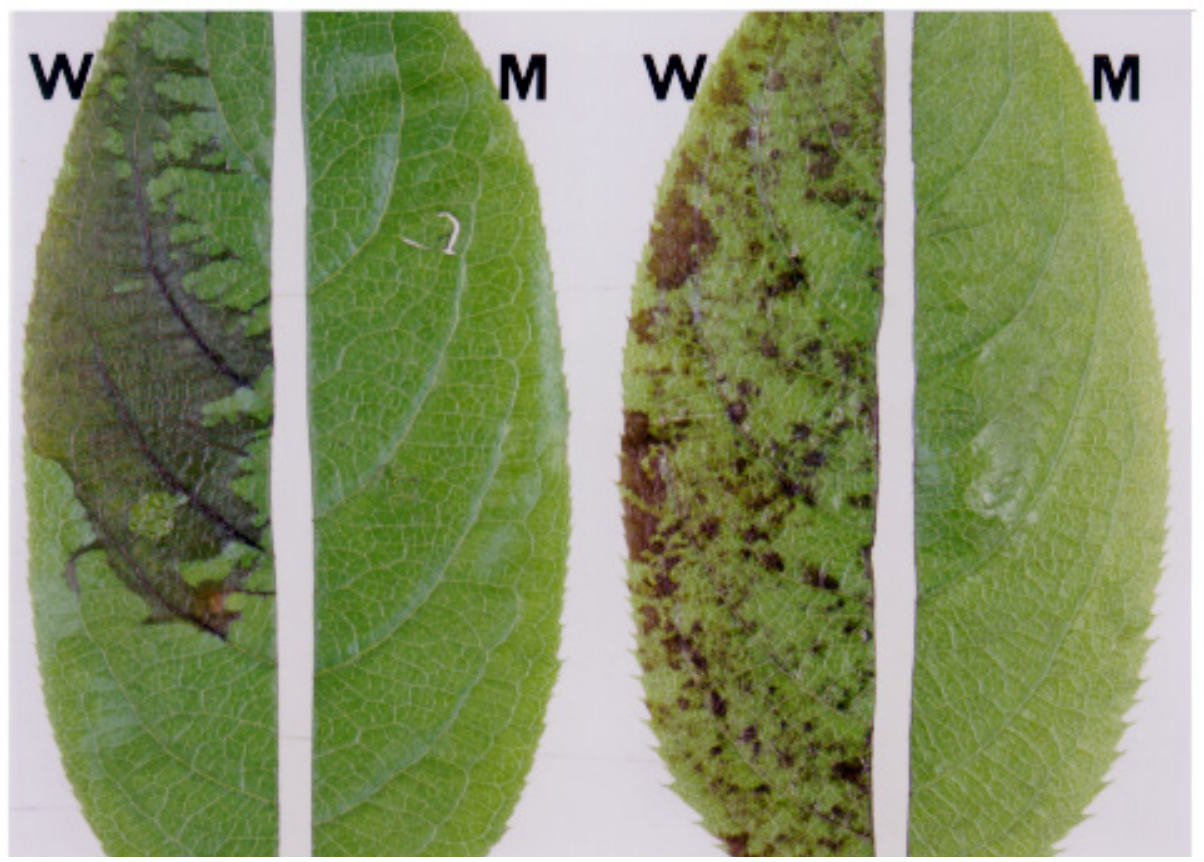

Fig. 6. AK-toxin production and pathogenicity of wild-type strain (W) and a mutant (M) produced by transformation with (A) the open reading frame (OFR) ORFR-targeting vector pGDTR or (B) the ORF3-targeting vector pGDT3. Leaves of susceptible pear cv. Nijisseiki were wounded slightly, treated with culture filtrates, and incubated in a moist box at $25^{\circ} \mathrm{C}$ for $20 \mathrm{~h}$ (left). Leaves were spray inoculated with spore suspensions (about $5 \times 10^{5}$ spores per $\mathrm{ml}$ ) and incubated in a moist box at $25^{\circ} \mathrm{C}$ for $20 \mathrm{~h}$ (right). 


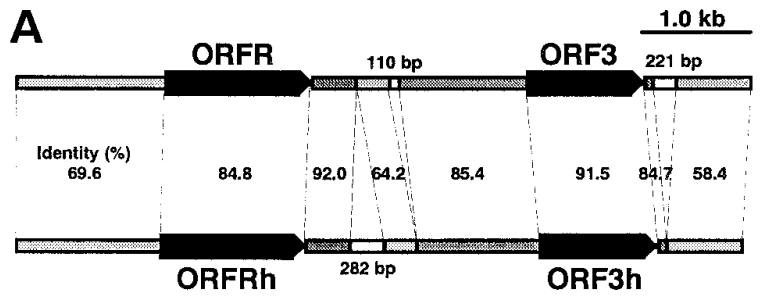

B

ORFR 1 :MLQCAPKKNERLRG SCंDFCंTQSSLRCंNKNK PSCंRR ORFRh 1: WLOCAPKKNERLRG SCDFCTOSKLRCNKNK PSCRR ORFR 36: ORFRh 36: CMIQQQVCVYSVARRTGRP PKHPRRADDSQEISGO $\begin{array}{ll}\text { ORFR } & \text { 71: HGEQDPVTSTPGGSCOQOSNHLLDVEGDGANFTLA } \\ \text { ORFRh } & \text { 71: GGHODPMSAPADSEOQS. SHLDLEGDTDETLV }\end{array}$ ORFR 106: DASTTAOGRETAAS SALDNAL UVGETFGFSSLLDD ORFR 105: DGRTAAERATVAP PVLDNAFLMGETEENSLLDD ORFR 141: PLIOSDDFLSFSLCMPPGEEE GHMASPRALNGSTG ORFRh 140: $\mathrm{g}$ ORFR 176: PCSPTVLSSIDVPHLPARFGFLESSVESGLHGRTC ORFRh 175: PCS PSALIS IDV POLPTNFRELESF I GSELHGRNE ORFR 211: PHLVEOPDK I VSS F SEMERT YDEGL TFSGIDSAI

ORFRh 210: PHPVEOPD.......EMEKTYDKGSI LIGLDSAI ORFR 246: NAV TNNGK G EPSA SGTMA AZ PHSK RQCFCSTSMSK ORFRh 237: NAI INNGK DSPS I SGNTVARPHSK HLCFCSMSMSK $\begin{array}{ll}\text { ORFR } & \text { 281: LQMUISHPTLCOKNSRARFDMTLFLEEVVFMTHRD } \\ \text { ORFRh } & \text { 272: LOVLUSHPALCRQNSRTPEDMVLFLEFFVGIHSD }\end{array}$

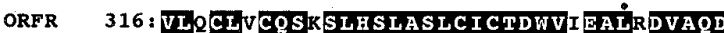
ORFRh 307: VLRCLICOSRSLHSLASLCICTDWVVEALVDVAOD ORFR 351 : LंSS GQDNLंGGFRAGLCPPRD KF SICVGRF VIDDQL ORFRh 342: LSLGODNLGGLRAEI CP PKNGSSIYVGRL ILADGF ORFR 386: RESCTRSI,VKYRLRKLVPIMDTMMKLNYRGAGGAI ORFRh 377: RESCTRSLVKYRLRKLI IMDMUI KLNYRGAGGAI ORFR 421: SQAIRTMVEDVRHK I ESALGMMEI

ORFRh 412: SOAIRTMVEDVRHKIESALGMMEL (74.1\%)
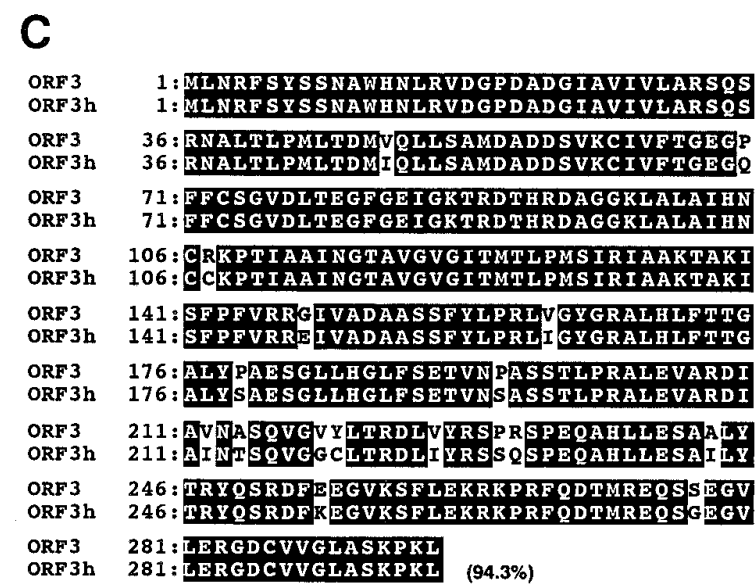

Fig. 7. Structure of open reading frame (ORF) ORFR/ORF3 and ORFRh/ORF3h regions. A, Identity of nucleotide sequences of regions containing ORFR and ORF3 in pcAKT-1 and ORFRh and ORF3h in pcAKT-2. B, Amino acid sequence alignment of proteins encoded by ORFR and ORFRh. Conserved amino acids are indicated as white letters on a black background. Zinc binuclear DNA-binding domain in amino terminal region and internal leucine zipper domain are underlined. Dots above sequences indicate highly conserved cysteines and leucines in these domains. Amino acid sequence identity is shown in parentheses. C, Amino acid sequence alignment of proteins encoded by ORF3 and ORF3h. Conserved amino acids are indicated as white letters on a black background. Amino acid sequence identity is shown in parentheses. able regions of ORFR and ORFRh $(78.1 \%$ identity in nucleotide sequence) were cloned to make pRS and $\mathrm{pRhS}$ (Fig. 1), and used to distinguish between the pcAKT-1 and pcAKT-2 genes in the following experiments.

The DNA gel blot of the wild type and pGDTR transformants used in Figure 4B was stripped of the pRPX probe and rehybridized with the $\mathrm{pRhS}$ insert. This probe hybridized to the 3.6$\mathrm{kb}$ band containing ORFRh in wild type and all $\mathrm{Tox}^{+}$transformants (Fig. 4C). In contrast, all Tox ${ }^{-}$transformants lacked the 3.6-kb band, indicating that ORFRh had been targeted in the Tox ${ }^{-}$pGDTR transformants. The genes encoding ORFR and ORFRh were designated $A K T R-1$ and $A K T R-2$, respectively.

ORF3 and ORF3h both consist of putative four exons of the same sizes (Fig. 1). Of three introns, only the second intron is different in size $($ ORF3 $=56 \mathrm{bp}$; ORF3h $=60 \mathrm{bp})$. ORF3 and ORF3h are $91.5 \%$ identical in nucleotide sequence of the exon plus intron regions and $94.3 \%$ identical in deduced amino acid sequence (Figs. 7A and C). As with the ORF3-encoded protein, the ORF3h-encoded protein reveals the highest similarity (27.4 and $24.2 \%$ identities, respectively) to enoyl-CoA hydratase of $R$. capsulatus (Beckman and Kranz 1991) and crotonase of $T$. thermosaccharolytium (GenBank accession no. CAB07495); 43 out of 44 amino acid residues that are identical in all the ORF3 product, enoyl-CoA hydratase, and crotonase are conserved in the ORF3h product (Fig. 3). The ORF3h product has the same PTS1 tripeptide (PKL) as the ORF3 product (Fig. 7C). The genes encoding ORF3 and ORF3h were designated $A K T 3-1$ and $A K T 3-2$, respectively.

The homology between AKTR-1 or AKT3-1 and AKTR-2 or $A K T 3-2$ extends beyond the ORFs in both directions (Fig. 7A). Between the AKTR and AKT3 genes are pcAKT-1- and pcAKT-2-specific insertions of 110 and $282 \mathrm{bp}$, respectively (Fig. 7A). There is also a pcAKT-1-specific insertion of 221 bp at the $3^{\prime}$ flanking region of $A K T 3-1$ (Fig. 7A).

Expression of the toxin biosynthesis genes.

Transcription of AKTR-1 and AKTR-2 in wild type and the pGDTR transformants was investigated by reverse transcription-polymerase chain reaction (RT-PCR). The AKTR-1specific primer pair (RTR-f/RTR-r) (Figs. 1 and 8A) yielded a 0.92-kb fragment of DNA from total RNA of not only the wild type and $\mathrm{Tox}^{+}$transformants but also Tox ${ }^{-}$transformants (Fig. 8B). The AKTR-2-specific primers (RTRh-f/RTRh-r) (Figs. 1 and $8 \mathrm{~A}$ ) generated a $0.89-\mathrm{kb}$ fragment of DNA from total RNA of the wild type and $\mathrm{Tox}^{+}$transformants, but not from the Tox ${ }^{-}$transformants (Fig. 8B). Transcription of AKT3-1 and AKT3-2 in wild type and pGDT3 transformants was also investigated by RT-PCR. The AKT3-1-specific primer pair (RT3-f/RT3-r) (Figs. 1 and 8C) produced a 0.63-kb fragment of DNA from total RNA of the wild type, Tox ${ }^{+}$transformants and Tox ${ }^{-}$transformants (Fig. 8D). The AKT3-2-specific primer pair (RT3h-f/RT3h-r) (Figs. 1 and 8C) generated a 0.63-kb fragment of DNA from total RNA of the wild type and Tox ${ }^{+}$ transformants, but not from the Tox ${ }^{-}$transformants (Fig. 8D). RT-PCR analysis, together with DNA gel blot analysis (Figs. 4 and 5), clearly demonstrated that AKTR-2 and AKT3-2 had been targeted in Tox $^{-}$mutants produced by integration of pGDTR and pGDT3, respectively.

To confirm introns in AKT3-1 and AKT3-2, primer pairs RT3f/RT3c-r and RT3h-f/RT3c-r were used for RT-PCR amplification of $A K T 3-1$ and $A K T 3-2$ cDNAs, respectively, from total 
RNA of wild type. RT3c-r (5'-TCAGAGCTTTG GCTTGGAA G-3') consists of sequences identical in the $3^{\prime}$ ends of AKT3-1 and $A K T 3-2$ ORFs (Fig. 1). RT-PCR amplification produced DNA fragments of the expected size $(0.92 \mathrm{~kb})$ by both primer pairs (data not shown). Sequencing of the RT-PCR products confirmed that the three introns in AKT3-1 and AKT3-2 are spliced.

\section{Chromosomal distribution of the $\boldsymbol{A K T}$ gene clusters.}

We showed previously that the wild-type strain has single copies of $A K T 1$ and $A K T 2$ and multiple copies of homologues (AKT1h and AKT2h) that are nonfunctional in toxin production (Tanaka et al. 1999). DNA gel blot analysis allowed the identification of polymorphisms between AKT1/AKT2-type and AKT1h/AKT2h-type restriction fragments (Tanaka et al. 1999). The 30 cosmid clones selected above were hybridized with p1EX and p2XS inserts containing the AKT1 and AKT2 internal fragments, respectively (Fig. 1). These probes did not hybridize to pcAKT-2, showing the lack of the $A K T 1$ and $A K T 2$ homologues on this cosmid. Among the remaining 29 clones, 19 and 26 clones hybridized to the AKT1 and AKT2
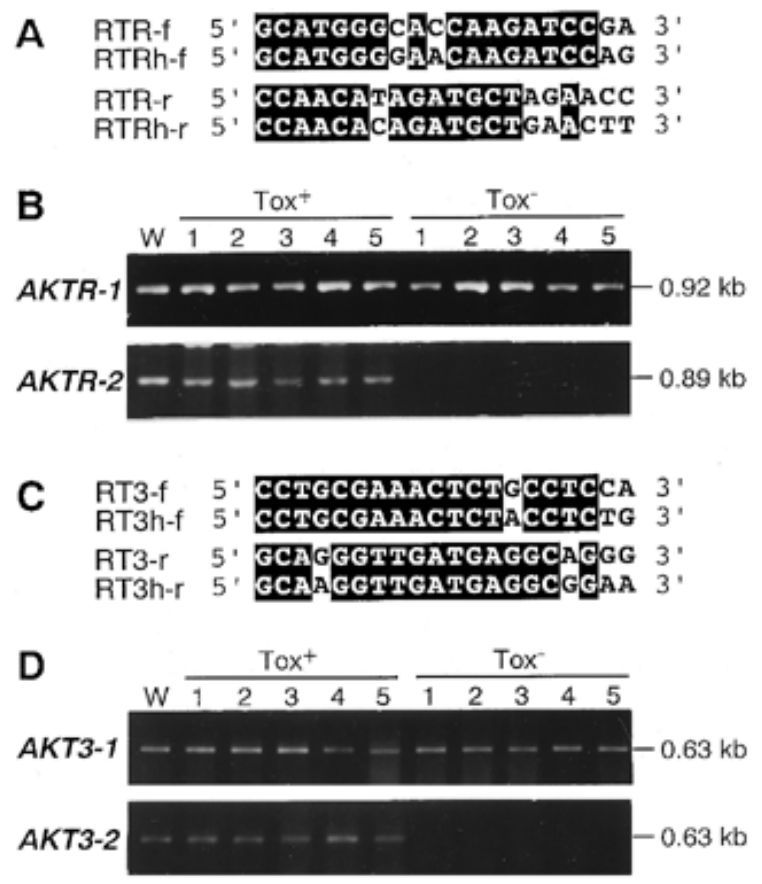

Fig. 8. Detection of transcripts from $A K T R$ and $A K T 3$ in $T^{-}{ }^{-}$mutants. Total RNA of the wild-type strain (W), Tox ${ }^{+}$transformants or Tox ${ }^{-}$transformants was used as a template for reverse transcription-polymerase chain reaction (RT-PCR) amplification. RT-PCR products were electrophoresed in a $1.2 \%$ agarose gel. A, Primers used for detection of AKTR1 and AKTR-2 transcripts. Primer pairs specific for AKTR-1 (RTRf/RTR-r) and AKTR-2 (RTRh-f/RTRh-r) were used in RT-PCR (see Figure 1). Nucleotides conserved between two primers are indicated as white letters on a black background. B, Detection of transcripts from $A K T R-1$ and $A K T R-2$ in the pGDTR transformants. C, Primers used for detection of the $A K T 3-1$ and $A K T 3-2$ transcripts. Primer pairs specific for AKT3-1 (RT3-f/RT3-r) and AKT3-2 (RT3h-f/RT3h-r) were used in RT-PCR (see Figure 1). Nucleotides conserved between two primers are indicated as white letters on a black background. D, Detection of transcripts from AKT3-1 and AKT3-2 in the pGDT3 transformants. probes, respectively. The diagnostic AKT1/AKT2-type restriction fragments were not present, however, showing that these clones contain homologues (AKT1h and AKT2h). Nucleotide sequences of the regions containing the AKTR-1 and AKT3-1 homologues in six clones, which had AKT1h and AKT2h, were analyzed. The analysis detected the same sequences as $A K T R-1$ and $A K T 3-1$ in all the six clones, suggesting the presence of multiple copies of AKTR-1 and AKT3-1 in the genome of the wild type. One clone, which carries AKT1h, AKT2h, AKTR-1, and AKT3-1, was named pcAKT-3.

To investigate the genomic distribution of the $A K T$ genes and their homologues, the chromosomal DNA of wild type was separated by pulsed-field gel electrophoresis and probed with p1EX, p2XS, pRS, pRhS, and p3HB containing internal fragments of AKT1, AKT2, AKTR-1, AKTR-2, and AKT3-1, respectively (Figs. 1 and 9). AKT3-1 and AKT3-2 could not be distinguished by DNA gel blot analysis, because their sequences are $91.5 \%$ identical. All probes hybridized to a single band of about $4.1 \mathrm{Mb}$, suggesting that these genes and their homologues all are located on a single chromosome (Fig. 9).

\section{Distribution of the $A K T R$ and $A K T 3$ homologues in A. alternata strains.}

DNA from 12 strains of the Japanese pear pathotype (Table 1) was digested with restriction enzymes, and the blots were probed with $\mathrm{pRS}, \mathrm{pRhS}$ and $\mathrm{p} 3 \mathrm{HB}$ containing the AKTR-1, $A K T R-2$, and $A K T 3-1$ fragments, respectively (Fig. 1). All the probes detected bands in all strains tested, and their hybridization patterns were similar to those of 15A (Fig. 10). Figure 10 shows DNA blots of representative seven strains of the Japanese pear pathotype. The AKTR-1 and AKTR-2 probes hybridized to $2.0-\mathrm{kb}$ and $3.6-\mathrm{kb}$ bands, respectively, in $P v u \mathrm{II}-$ digested DNA of all strains (Fig. 10A and B). There were no

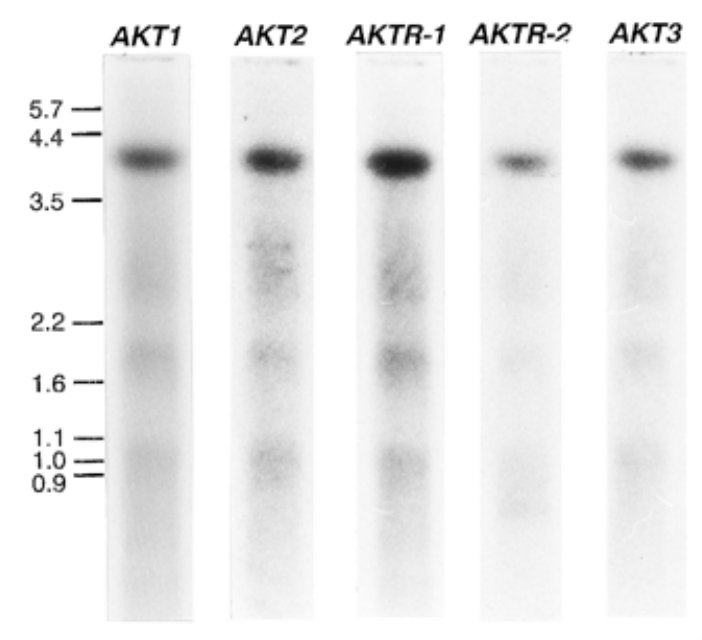

Fig. 9. Chromosomal distribution of genes involved in AK-toxin biosynthesis. Chromosome-sized DNA molecules were separated by contour-clamped homogeneous electric field (CHEF) electrophoresis, and the blots were hybridized with the AKT1, AKT2, AKTR-1, AKTR-2, and AKT3-1 fragments from $\mathrm{p} 1 \mathrm{EX}, \mathrm{p} 2 \mathrm{XS}, \mathrm{pRS}, \mathrm{pRhS}$, and $\mathrm{p} 3 \mathrm{HB}$, respectively (see Figure 1). Sizes (in Mb) of marker DNAs (chromosome-sized DNAs of Schizosaccharomyces pombe and Saccharomyces cerevisiae) are indicated on left. 
apparent differences in signal intensity of the $2.0-\mathrm{kb}$ or $3.6-\mathrm{kb}$ fragment between $15 \mathrm{~A}$ and each of others. The AKT3-1 probe hybridized strongly to $2.5-\mathrm{kb}$ bands and weakly to $4.0-\mathrm{kb}$ bands in SphI-digested DNA of all strains (Fig. 10C). The AKT3-2 probe (p3hS) (Fig. 1) also hybridized strongly to 2.5$\mathrm{kb}$ bands and weakly to $4.0-\mathrm{kb}$ bands (data not shown). This analysis, together with the analysis of the 30 cosmid clones of $15 \mathrm{~A}$, strongly suggests that all strains contain multiple copies of AKTR- 1 and AKT3- 1 and single copies of AKTR-2 and AKT3-2.

Nineteen strains from an additional six pathotypes and five nonpathogenic strains of $A$. alternata (Table 1) were also analyzed for distribution of the gene homologues. Figure 10 shows DNA blots of a representative strain each of the six pathotypes and a nonpathogenic A. alternata strain. The AKTR-1 and $A K T 3-1$ probes detected their homologues in all strains of the tangerine pathotype, which produces ACT-toxin (Pegg 1966; Kohmoto et al. 1993), and of the strawberry pathotype, which produces AF-toxin (Maekawa et al. 1984; Nakatsuka et al. 1986) (Fig. 10A and C). The AKTR-2 probe, however, did not hybridize to DNA of these pathotype strains, suggesting AKTR2 is unique for the Japanese pear pathotype (Fig. 10B). Strains from other pathotypes and nonpathogenic A. alternata had no detectable homologues of these genes (Fig. 10).

\section{DISCUSSION}

Previously, we described a cosmid clone pcAKT-1, which contains the AKT1 and AKT2 genes essential for AK-toxin biosynthesis (Tanaka et al. 1999). Here we identified two additional genes, $A K T R-1$ and $A K T 3-1$, downstream of $A K T 2$ in pcAKT-1. Transformation of the wild-type strain $15 \mathrm{~A}$ with the AKTR-1- and AKT3-1-targeting vectors produced Tox ${ }^{-}$transformants. However, DNAs targeted by the vectors in Tox transformants were not the same as the transforming AKTR-1 and $A K T 3-1$ DNA. A cosmid clone pcAKT-2 carrying the actual targeted genes, $A K T R-2$ and $A K T 3-2$, was isolated. Sequence analysis showed that $A K T R-2$ and $A K T 3-2$ are highly similar, but not identical to $A K T R-1$ and $A K T 3-1$, respectively, indicating that the vectors were targeted to heterologous locations. We previously analyzed homologous recombination of transforming DNA in strain 15A with its $B R M 1$ gene, which is essential for melanin biosynthesis (Kimura and Tsuge 1993; Shiotani and Tsuge 1995). Targeting vectors were constructed by inserting 0.6- to 3.1-kb internal BRM1 fragments into a plasmid containing $h p h$ as a selectable marker. When circular plasmids were used, melanin-deficient transformants accounted for 30 to $80 \%$, correlating closely with the size of the BRM1 segment in the vectors. This result demonstrated that homologous DNA of $0.6 \mathrm{~kb}$ could be enough for targeted integration of exogenous DNA in this fungus (Shiotani and Tsuge 1995). Effect of the homology level on targeted integration of exogenous DNA has not been examined. The AKT3-1targeting vector contained a $1.0-\mathrm{kb}$ segment of $A K T 3-1$, which has $91.5 \%$ identity in nucleotide sequence to the corresponding region of AKT3-2. The AKTR-1-targeting vector had hph flanked by the $5^{\prime}$ sequence $(0.8 \mathrm{~kb})$ and $3^{\prime}$ sequence $(1.3 \mathrm{~kb})$ from ORFR. The $5^{\prime}$ and $3^{\prime}$ sequences reveal 76.1 and $67.0 \%$ identities to the corresponding regions of $A K T R-2$, respectively. Thus, these identities and lengths could be enough for homologous integration of exogenous DNA in this fungus.

DNA gel blot analysis revealed restriction fragment length polymorphisms (RFLPs) between AKTR-1/AKT3-1 and AKTR-2/AKT3-2 types. Among 30 positive clones selected from a cosmid genomic library of $15 \mathrm{~A}$ probed with AKT3-1, only pcAKT-2 had the AKTR-2/AKT3-2 type of restriction fragments; the remaining 29 clones had the AKTR-1/AKT3-1 type. Sequence analysis of six out of these 29 clones showed the presence of the same sequences as AKTR-1 and AKT3-1. DNA gel blot analysis of genomic DNA of $15 \mathrm{~A}$ showed that the AKT3-1 and AKT3-2 probes both hybridized strongly to the $A K T 3$-1-type DNA and weakly to the AKT3-2-type DNA. These results indicate that the wild-type strain has multiple copies of AKTR-1 and AKT3-1, and fewer copies of AKTR-2 and AKT3-2.

We have previously demonstrated that the wild-type strain 15A has single copies of $A K T 1$ and $A K T 2$, and multiple copies of their homologues, AKT1h and AKT2h (Tanaka et al. 1999). The gene targeting experiments showed that toxin biosynthesis requires $A K T 1$ and $A K T 2$, but not their homologues (Tanaka et al. 1999). Although the AKT1- or AKT2-targeted transformants maintained the homologues in their genomes, RT-PCR analysis could not detect RNA transcription from these homologues (Tanaka et al. 1999). Cosmid pcAKT-1 carries $A K T 1, A K T 2, A K T R-1$, and $A K T 3-1$, in that order, within a $12-\mathrm{kb}$ region. Cosmid pcAKT-2 contains only $A K T R-2$ and AKT3-2. Cosmid pcAKT-3 contains AKT1h, AKT2h, AKTR1, and $A K T 3-1$. DNA gel blot analysis with pulsed field gel
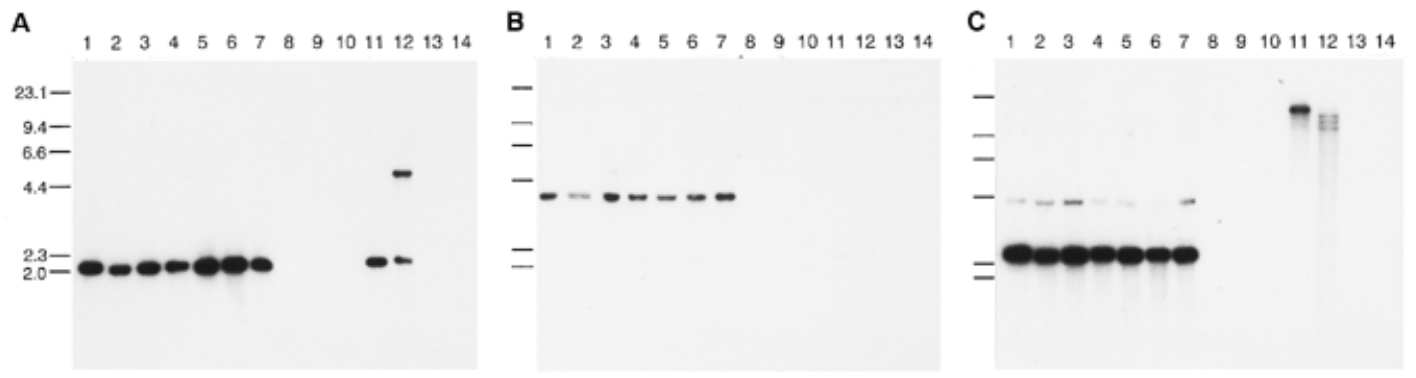

Fig. 10. Distribution of the AKTR-1, AKTR-2, and AKT3 homologues in Alternaria alternata strains. Total DNA of each strain was digested with (A and B) PvuII or (C) $S p h \mathrm{I}$, and separated in a $0.8 \%$ agarose gel. Blots were probed with the (A) AKTR-1, (B) AKTR-2, and (C) AKT3-1 fragments from pRS, $\mathrm{pRhS}$, and p3HB, respectively (see Figure 1). Sizes (in kb) of marker DNA fragments (HindIII-digested $\lambda$ DNA) are indicated on left. Lanes 1-7, 15A, T88-11, T88-107, Nu89-22, N18, G31, and G90-A2, respectively, of the Japanese pear pathotype; lanes 8-14, AM-1 of the apple pathotype, AT204 of the tobacco pathotype, ATCC38962 of the rough lemon pathotype, ATCC38963 of the tangerine pathotype, O-187 of the strawberry pathotype, AL-4 of the tomato pathotype, and IFO031188 of nonpathogenic A. alternata, respectively (see Table 1). 
electrophoresis showed that these genes and their homologues are all on the same 4.1-Mb chromosome. The 4.1-Mb chromosome is one of 11 chromosomes also estimated previously in 15A (Adachi et al. 1996; Akamatsu et al. 1999). These results imply that the genomic region controlling AK-toxin biosynthesis is structurally and functionally complex. It is possible that there is a cluster consisting of a set of the genes essential for AK-toxin biosynthesis, and that pcAKT-1 and pcAKT-2 are versions that contain only parts of the cluster. Taga and Murata (1994) reported successful use of fluorescence in situ hybridization (FISH) for allocation of rDNA to a particular

Table 1. Strains of Alternaria alternata used in this study

\begin{tabular}{|c|c|c|}
\hline \multirow[b]{2}{*}{ Pathotype and strain ${ }^{a}$} & \multicolumn{2}{|c|}{ Origin } \\
\hline & Location & Source $^{b}$ \\
\hline \multicolumn{3}{|l|}{ Japanese pear (AK-toxin) } \\
\hline $15 \mathrm{~A}$ & Tottori & $\mathrm{TU}$ \\
\hline T88-11 & Tottori & THES \\
\hline $\mathrm{T} 88-52$ & Tottori & THES \\
\hline T88-58 & Tottori & THES \\
\hline T88-107 & Tottori & THES \\
\hline $91 \mathrm{H}-18$ & Aichi & NU \\
\hline $91 \mathrm{H}-27$ & Aichi & NU \\
\hline Nu89-22 & Aichi & NU \\
\hline N18 & Aichi & NU \\
\hline G16 & Gifu & NU \\
\hline G31 & Gifu & NU \\
\hline G90-A2 & Gifu & NU \\
\hline \multicolumn{3}{|l|}{ Apple (AM-toxin) } \\
\hline AM-1 & Aichi & NU \\
\hline IFO08984 & Unknown $^{c}$ & IFO \\
\hline $\mathrm{Ku}-16 \mathrm{Ro}$ & Aomori & FTRS \\
\hline AM91-1 & Nagano & NFTES \\
\hline \multicolumn{3}{|l|}{ Tobacco (AT-toxin) } \\
\hline AT-204 & Aichi & NU \\
\hline No. $122-2$ & Tochigi & JT \\
\hline $86-1$ & Kanagawa & JT \\
\hline ATL-10 & Tottori & JT \\
\hline IFO6149 & Unknown $^{\mathrm{c}}$ & IFO \\
\hline \multicolumn{3}{|c|}{ Rough lemon (ACR-toxin) } \\
\hline ATCC38962 & United States & ATCC \\
\hline \multicolumn{3}{|l|}{ Tangerine (ACT-toxin) } \\
\hline ATCC38963 & United States & ATCC \\
\hline \multicolumn{3}{|l|}{ Strawberry (AF-toxin) } \\
\hline $\mathrm{O}-187$ & Iwate & TU \\
\hline M-30 & Tottori & TU \\
\hline $\mathrm{T}-32$ & Tottori & TU \\
\hline NAF-2 & Aichi & NU \\
\hline NAF-3 & Aichi & NU \\
\hline \multicolumn{3}{|l|}{ Tomato (AAL-toxin) } \\
\hline AL-4 & Mie & NU \\
\hline AL-12 & Mie & NU \\
\hline No. 91080804 & Mie & MARC \\
\hline \multicolumn{3}{|l|}{ Nonpathogen } \\
\hline IFO031188 & Kagawa & IFO \\
\hline IFO031189 & Unknown $^{c}$ & IFO \\
\hline ATCC66981 & United States & ATCC \\
\hline ATCC66982 & United States & ATCC \\
\hline O-94 & Tottori & $\mathrm{TU}$ \\
\hline
\end{tabular}

${ }^{a}$ Host-specific toxin produced by each pathotype is shown in parentheses.

b TU, Tottori University, Tottori, Japan; THES, Tottori Horticultural Experimental Station, Tottori, Japan; NU, Nagoya University, Aichi, Japan; IFO, Institute for Fermentation, Osaka, Japan; FTRS, Fruit Tree Research Station, Ibaraki, Japan; NFTES, Nagano Fruit Tree Experiment Station, Nagano, Japan; JT, Japan Tobacco, Kanagawa, Japan; ATCC, American Type Culture Collection, MD; MARC, Mie Agricultural Research Center, Mie, Japan (Kusaba and Tsuge 1994; Adachi et al. 1996).

${ }^{c}$ Unknown, but in Japan. chromosome in the A. alternata genome. We are further investigating the chromosomal distribution of the toxin biosynthesis genes and their homologues by the FISH method.

Complexity at loci controlling host-specific toxin biosynthesis has been reported for Cochliobolus heterostrophus race T (Tzeng et al. 1992; Chang and Bronson 1996; Yoder 1998; Kodama et al. 1999) and C. carbonum race 1 (Ahn and Walton 1996; Walton et al. 1998). In C. heterostrophus, early genetic studies indicated that a single Mendelian locus, Toxl, controls T-toxin biosynthesis (Leach et al. 1982). Molecular data, however, revealed that Toxl is two loci (ToxlA and Tox 1B), one on each of two chromosomes in race $\mathrm{T}$ that are translocated with respect to their counterparts in race $\mathrm{O}$, which does not produce T-toxin (Tzeng et al. 1992; Chang and Bronson 1996; Yoder 1998; Kodama et al. 1999). ToxlA carries the $P K S 1$ gene, which encodes a Type I polyketide synthase; Tox $1 B$ carries the $D E C l$ gene, which encodes a decarboxylase ( $\mathrm{Lu}$ et al. 1994; Yang et al. 1996; Yoder 1998; Kodama et al. 1999). In C. carbonum, a single locus, Tox2, controlling HC-toxin biosynthesis was defined by segregation analysis (Nelson and Ullstrup 1961; Scheffer et al. 1967). Molecular studies showed that Tox2 carries two or three copies each of HTS1, TOXA, TOXC, TOXE, and TOXF, known to be essential for toxin biosynthesis (Panaccione et al. 1992; Scott-Craig et al. 1992; Ahn and Walton 1996, 1997,; 1998; Pitkin et al. 1996; Cheng et al. 1999). All copies of these genes are located in a region of $>540 \mathrm{~kb}$ and are functional (Ahn and Walton 1996; Walton et al. 1998). Thus, the genomic regions controlling biosynthesis of T-toxin, HCtoxin, and AK-toxin in three fungi all are not simple, genetic loci, but instead are large, complex regions of DNA.

AKTR-1 and AKT3-1 sequences are highly similar to, but significantly different from, those of AKTR-2 and AKT3-2, respectively ( 84.8 and $91.5 \%$ ). Similarity between $A K T R-1$ or AKT3-1 and AKTR-2 or AKT3-2 extends beyond the coding sequence in both directions; however, the conserved regions are divided by the AKTR-1/AKT3-1- and AKTR-2/AKT3-2specific insertions. Thus, it is unlikely that variability between the AKTR-1/AKT3-1 and AKTR-2/AKT3-2 regions originated by simple mutation. Although the gene targeting experiments showed that $A K T R-2$ and $A K T 3-2$, at least, are essential for toxin biosynthesis, RT-PCR experiments detected not only $A K T R-2$ and AKT3-2 mRNAs but also AKTR-1 and AKT3-1 mRNAs in the wild type. Thus, it is possible that $A K T R-1$ and AKT3-1 might encode proteins that have different functions from those encoded by AKTR-2 and AKT3-2 and might be essential for toxin biosynthesis. However, the functional characterization of $A K T R-1$ and $A K T 3-1$ by gene targeting is very difficult or perhaps impossible, because of the presence of multiple copies of these genes.

The AKTR-1- and AKTR-2-encoded proteins (AktR-1 and AktR-2) contain the zinc binuclear cluster DNA-binding domain typical in the $\mathrm{Zn}$ (II)2Cys6 family proteins (Todd and Andrianopoulos 1997). Proteins with this domain are known to be typical regulatory factors in fungi and to be involved in a diverse array of cellular processes, including primary and secondary metabolism, drug resistance, and meiotic development in fungi (Todd and Andrianopoulos 1997). The presence of zinc binuclear cluster domain in AKTR-1 and AKTR-2 suggests that they bind to DNA to regulate expression of other pathway genes, but this has not yet been experimentally demonstrated. 
AktR-1 and AktR-2 have lower identity (65.6\%) in the internal regions containing the leucine zipper domains, which are necessary for homodimerization or heterodimerization (Todd and Andrianopoulos 1997). DNA gel blot analysis with probes corresponding to this variable region distinguished between AKTR-1 and AKTR-2. The AKTR-1 homologues were found in the strawberry and tangerine pathotypes as well as the Japanese pear pathotype. Their toxins have a common moiety, 9,10-epoxy-8-hydroxy-9-methyl-decatrienoic acid (Nakashima et al. 1985; Nakatsuka et al. 1986; Kohmoto et al. 1993). In contrast, the AKTR-2 homologues were detected only in the Japanese pear pathotype. These results suggest that AktR-1 and AktR-2 are required for expression of pathway genes for biosynthesis of 9,10-epoxy-8-hydroxy-9-methyldecatrienoic acid and AK-toxin-specific moiety, respectively. The AKTR-2-targeted mutants, however, failed to produce 9,10-epoxy-8-hydroxy-9-methyl-decatrienoic acid, indicating that AktR-2 is required for biosynthesis of this moiety. The zinc binuclear cluster domain has been shown to determine DNA binding specificity for numerous proteins in this family (Todd and Andrianopoulos 1997). AktR-1 and AktR-2 have $98.3 \%$ identity in the amino terminal regions (59 amino acids), including this domain, with only one amino acid residue difference. Detection of DNA-binding activity of AktR-1 and AktR-2 and identification of their binding sequences are required to assess the role of these proteins in regulation of toxin pathway genes and in toxin biosynthesis.

The AKT3-1- and AKT3-2-encoded proteins (Akt3-1 and Akt3-2) show homology to members of the hydratase/isomerase family, such as enoyl-CoA hydratases, crotonases, naphthoate synthases, and 4-chlorobenzoyl-CoA dehalogenases (Müller-Newen and Stoffel 1993). This family consists of enzymes that use CoA derivatives as substrates, and their amino acid sequences have low, but significant, homology one another (Müller-Newen and Stoffel 1993). This family contains enzymes involved in the fatty acid modification (MüllerNewen and Stoffel 1993). The AKT3-2-targeted, Tox ${ }^{-}$mutants failed to produce 9,10-epoxy-8-hydroxy-9-methyl-decatrienoic acid. The AKT3 homologues were also found in the strawberry and tangerine pathotypes. Thus, Akt3-2 is likely to be involved in 9,10-epoxy-8-hydroxy-9-methyl-decatrienoic acid biosynthesis via modification of its earlier precursor.

Akt3-1 and Akt3-2 terminate with a peroxisomal targeting signal type 1 (PTS1)-like tripeptide PKL that conforms to the PTS1 consensus motif established for S. cerevisiae (Elgersma et al. 1996). These proteins show similarity to enoyl-CoA hydratases involved in $\beta$-oxidation pathway of fatty acids, which can take place in peroxisomes and/or mitochondria in eukaryotes (Kunau et al. 1988). The peroxisomal enoyl-CoA hydratase is part of the trifunctional enzyme, which consists of 3-hydroxyacyl-CoA dehydrogenase, enoyl-CoA hydratase, and 3,2-trans-enoyl-CoA isomerase domains (Osumi et al. 1985; Müller-Newen and Stoffel 1993). Although Akt3-1 and Akt3-2 have the PTS1, their amino acid sequences are more similar to those of the mitochondrion-type enzymes than to those of the peroxisome-type enzymes, indicating that Akt3-1 and Akt3-2 are novel proteins of the hydratase/isomerase family. The $A K T 1$ - and $A K T 2$-encoded proteins (Akt1 and Akt2) also have the PTS1 tripeptides SKI and SKL, respectively, at the carboxy termini (Tanaka et al. 1999). The presence of the PTS1 in Akt1, Akt2, and Akt3 suggests that 9,10- epoxy-8-hydroxy-9-methyl-decatrienoic acid is biosynthesized in peroxisomes. We are now investigating peroxisomal import of these proteins with green fluorescent protein fusions.

The Japanese pear, strawberry, and tangerine pathotypes are good models for studying intraspecific variation and evolution of pathogenicity in A. alternata. We previously measured genetic relatedness among the A. alternata pathotypes on the basis of three DNA markers: RFLPs of nuclear rDNA, nucleotide sequence variation in rDNA internal transcribed spacer regions, and RFLPs of mitochondrial DNA (Kusaba and Tsuge 1994, 1995, 1997). None of these markers could differentiate strains in correlation with pathotypes: singlepathotype populations carried multiple DNA variants, and different pathotype populations shared similar variation (Kusaba and Tsuge 1994, 1995, 1997). These data suggest that singlepathotype populations of $A$. alternata are not clonal. Comparison of the structure, function, and chromosomal distribution of the toxin biosynthesis genes from three pathotypes is of great importance in the study of the evolution of toxin biosynthesis and the origin of genes for toxin biosynthesis. Isolation of the $A K T$ gene homologues from the strawberry and tangerine pathotypes is now in progress.

\section{MATERIALS AND METHODS}

\section{Fungal strains.}

A total of 36 strains from seven pathotypes and nonpathogenic A. alternata were used in this study (Table 1). Strain $15 \mathrm{~A}$ of the Japanese pear pathotype was the source of the AKtoxin biosynthesis genes (Tanaka et al. 1999). The others were used for analysis of distribution of the gene homologues. Strains were routinely maintained on potato dextrose agar (PDA; Difco, Detroit, MI).

\section{Plasmids and genomic libraries.}

Transformation vector pSH75 (Kimura and Tsuge 1993) was used for construction of gene targeting vectors in $A$. alternata. pSH75 carries the hygromycin B resistance gene (hph), which is fused to the A. nidulans trpC promoter and terminator (Cullen et al. 1987; Kimura and Tsuge 1993). p1EX contains the $1.1-\mathrm{kb}$ fragment internal to $A K T 1$, and p2XS contains the $0.9-\mathrm{kb}$ fragment internal to $A K T 2$ (Fig. 1) (Tanaka et al. 1999). The 1.6-kb PstI-XbaI fragment internal to ORFR was cloned in the PstI-XbaI site of pBluescript KS+ (Stratagene, La Jolla, CA) to make pRPX (Fig. 1). The 0.9-kb fragments internal to ORFR and ORFRh were amplified from pcAKT-1 and pcAKT-2, respectively, with the following primer pairs: RTR-f/RTR-r for ORFR and RTRh-f/RTRh-r for ORFRh (Figs. 1 and 8A). The PCR products were cloned in pGEM-T Easy vector (Promega, Madison, WI) to produce $\mathrm{pRS}$ and $\mathrm{pRhS}$ containing the ORFR and ORFRh fragments, respectively (Fig. 1). The 1.3-kb XbaI-XhoI fragment containing the $3^{\prime}$ region of ORFR was cloned in the XbaI-XhoI site of pSH75 to produce pRXX-SH (Fig. 4A). The 0.8-kb Pst I fragment containing the $5^{\prime}$ region of ORFR was cloned in pBluescript KS+ to make pPs0.9 (Fig. 4A). The pPs0.9 insert was cut out with BamHI and EcoRV (restriction enzyme sites in pBluescript $\mathrm{KS}+$ ) and cloned in the BglII-EcoRV site of the pRXX-SH to make the ORFR targeting vector pGDTR (Fig. 4A). The 1.0-kb HindIII-BamHI fragment internal to ORF3 was cloned in pBluescript KS+ to produce p3HB (Fig. 1). The 
same fragment was cloned in the HindIII-BamHI site of pSH75 to produce the ORF3 targeting vector pGDT3 (Fig. $5 \mathrm{~A})$. The $0.75-\mathrm{kb}$ fragment of ORF3h was amplified from pcAKT-2 with the primer pair RT3h-f/RT-3h-r and cloned in pGEM-T easy to produce p3hS (Fig. 1).

A genomic cosmid library of strain 15A has been previously described (Kimura and Tsuge 1993). The cosmid clone pcAKT-1 was isolated from the library and characterized to contain the AKT1 and AKT2 genes (Tanaka et al. 1999).

\section{Fungal transformation.}

Protoplast preparation and transformation of A. alternata were performed by the methods previously described (Tsuge et al. 1990; Shiotani and Tsuge 1995). Colonies that appeared 5 to 10 days after plating on the selective regeneration media (Tsuge et al. 1990) were transferred to PDA containing hygromycin B at $100 \mu \mathrm{g}$ per $\mathrm{ml}$, and transformants were selected after incubation at $25^{\circ} \mathrm{C}$ for 5 days.

\section{Assay for pathogenicity and AK-toxin production.}

Pathogenicity of wild type and transformants was assayed with leaves of Japanese pear cultivar Nijisseiki as previously described (Hayashi et al. 1990; Tanaka et al. 1999).

AK-toxin production during growth in potato dextrose broth (PDB; Difco) was tested with a bioassay involving leaves of Japanese pear cultivar Nijisseiki, which is the most sensitive method for detection of toxin (Hayashi et al. 1990), as previously described (Tanaka et al. 1999). AK-toxin and 9,10epoxy-8-hydroxy-9-methyl-decatrienoic acid in culture filtrates were extracted and quantified by reverse-phase high performance liquid chromatography as previously described (Tanaka et al. 1999).

\section{DNA manipulations.}

Isolation of total DNA and RNA from A. alternata, isolation of plasmid and cosmid DNAs, agarose gel electrophoresis, screening of cosmid libraries, and DNA gel blot hybridization were performed as previously described (Tanaka et al. 1999). Chromosome-sized DNA molecules were prepared, fractionated by pulsed-field gel electrophoresis with a contour-clamped homogeneous electric field (CHEF) apparatus (CHEF-DRII; BioRad Laboratories, Hercules, CA) and subjected to hybridization as described by Adachi et al. (1996) and Akamatsu et al. (1999). All blots were washed twice in $2 \times$ SSPE $(1 \times$ SSPE $=180 \mathrm{mM}$ $\mathrm{NaCl}, 10 \mathrm{mM} \mathrm{NaH} \mathrm{PO}_{4}$ [pH 7.7] and $1 \mathrm{mM}$ EDTA) plus $0.1 \%$ sodium dodecyl sulfate at $65^{\circ} \mathrm{C}$ for $10 \mathrm{~min}$ and once in $1 \times \mathrm{SSPE}$ plus $0.1 \%$ sodium dodecyl sulfate at $65^{\circ} \mathrm{C}$ for $10 \mathrm{~min}$.

RT-PCR was performed with the RNA PCR Kit version 2.1 (Takara, Ohtsu, Japan) according to the manufacturer's instructions. The following primer pairs were used: RTR-f/RTRr for $A K T R-1$, RTRh-f/RTRh-r for $A K T R-2$, RT3-f/RT3-r and RT3-f/RT3c-r for AKT3-1, and RT3h-f/RT3h-r and RT3hf/RT3c-r for $A K T 3-2$ (Figs. 1 and 8).

For analysis of nucleotide sequences, DNA was cloned in pBluescript KS+ or pGEM-T Easy. DNA sequences were determined with the PRISM Dye Termination Cycle Sequencing Ready Reaction Kit (Applied Biosystems, Warrington, UK) and an automated fluorescent DNA sequencer (Model 373A, Applied Biosystems) according to the manufacturer's instructions. DNA sequences were analyzed with BLAST (Altschul et al. 1990). Alignment of nucleotide and amino acid se- quences was made with the CLUSTAL W program (Thompson et al. 1994).

\section{ACKNOWLEDGMENTS}

We express our special thanks to Gillian Turgeon for critical suggestions and reading of the manuscript. We thank Mikihiro Yamamoto and Kazuya Akimitsu for critical suggestions and discussion; Hirofumi Yoshioka, Kazuhito Kawakita, and Noriyuki Doke for valuable suggestions; and the Radioisotope Research Center, Nagoya University, for technical assistance. This work was supported by grants-in-aid for Scientific Research from the Ministry of Education, Science, Sports and Culture of Japan (T. T.), special coordination funds for promoting science and technology from the Science and Technology Agency of Japan (T. T.), Daiko Foundation (T. T.), and a Research Fellowship of Japan Society for the Promotion of Science for Young Scientists (A. T.).

\section{LITERATURE CITED}

Adachi, Y., Watanabe, H., and Tsuge, T. 1996. Relationships between genetic polymorphisms and fungicide resistance within Alternaria alternata. Phytopathology 86:1248-1254.

Ahn, J.-H., and Walton, J. D. 1996. Chromosomal organization of TOX2, the complex locus controlling host-selective toxin biosynthesis in Cochliobolus carbonum. Plant Cell 8:887-897.

Ahn, J.-H., and Walton, J. D. 1997. A fatty acid synthase gene in Cochliobolus carbonum required for production of HC-toxin, cyclo(Dprolyl-L-alanyl-D-alanyl-L-2-amino-9,10-epoxi-8-oxodecanoyl). Mol. Plant-Microbe Interact. 10:207-214.

Ahn, J.-H., and Walton, J. D. 1998. Regulation of cyclic peptide biosynthesis and pathogenicity in Cochliobolus carbonum by TOXEp, a novel protein with bZIP basic DNA-binding motif and four ankyrin repeats. Mol. Gen. Genet. 260:462-469.

Akamatsu, H., Taga, M., Kodama, M., Johnson, R., Otani, H., and Kohmoto, K. 1999. Molecular karyotypes for Alternaria plant pathogens known to produce host-specific toxins. Curr. Genet. 35:647-656.

Altschul, S. F., Gish, W., Miller, W., Myers, E. W., and Lipman, D. J. 1990. Basic local alignment sequence tool. J. Mol. Biol. 215:403-410.

Beckman, D. L., and Kranz, R. G. 1991. A bacterial homolog to the mitochondrial enoyl-CoA hydratase. Gene 107:171-172.

Bruchez, J. J. P., Eberle, J., and Russo, V. E. 1993. Regulatory sequences in the transcription of Neurospora crassa gene: CAAT box, TATA box, intron, poly(A) tail formation sequences. Fungal Genet. Newsl. 40:89-96.

Chang, H.-R., and Bronson, C. R. 1996. A reciprocal translocation and possible insertion(s) tightly associated with host-specific virulence in Cochliobolus heterostrophus. Genome 39:549-557.

Cheng, Y.-Q., Ahn, J.-H., and Walton, J. D. 1999. A putative branchedchain-amino-acid transaminase gene required for HC-toxin biosynthesis and pathogenicity in Cochliobolus carbonum. Microbiology 145: 3539-3546

Cullen, D., Leong, S. A., Wilson, L. J., and Henner, D. J. 1987. Transformation of Aspergillus nidulans with the hygromycin-resistance gene, $h p h$. Gene 57:21-26.

Elgersma, Y., Vos, A., van den Berg, M., van Roemund, C. W. T., van der Sluijs, P., Distel, B., and Tabak, H. F. 1996. Analysis of the carboxyl-terminal peroxisomal targeting signal 1 in a homologous context in Saccharomyces cerevisiae. J. Biol. Chem. 271:26375-26382.

Feng, B.-N., Nakatsuka, S., Goto, T., Tsuge, T., and Nishimura, S. 1990. Biosynthesis of host-selective toxins produced by Alternaria alternata pathogens. I. $(8 R, 9 S)-9,10$-epoxy-8-hydroxy-9-methyl-deca-( $2 E$, $4 Z, 6 E)$-trienoic acid as a biological precursor of AK-toxins. Agric. Biol. Chem. 54:845-848.

Hayashi, N., Tanabe, K., Tsuge, T., Nishimura, S., Kohmoto, K., and Otani, H. 1990. Determination of host-selective toxin production during spore germination of Alternaria alternata by high-performance liquid chromatography. Phytopathology 80:1088-1091.

Keller, N. P., and Hohn, T. M. 1997. Metabolic pathway gene clusters in filamentous fungi. Fungal Genet. Biol. 21:17-29.

Kimura, N., and Tsuge, T. 1993. Gene cluster involved in melanin biosynthesis of the filamentous fungus Alternaria alternata. J. Bacteriol. 175:4427-4435.

Kodama, M., Rose, M. S., Yang, G., Yun, S. H., Yoder, O. C., and Turgeon, B. G. 1999. The translocation-associated Tox1 locus of Coch- 
liobolus heterostrophus is two genetic elements on two different chromosomes. Genetics 151:585-596.

Kohmoto, K., Itoh, Y., Shimomura, N., Kondoh, Y., Otani, H., Kodama, M., Nishimura, S., and Nakatsuka, S. 1993. Isolation and biological activities of two host-specific toxins from the tangerine pathotype of Alternaria alternata. Phytopathology 83:495-502.

Kohmoto, K., Otani, H., and Tsuge, T. 1995. Alternaria alternata pathogens. Pages 51-63 in: Pathogenesis and Host Specificity in Plant Diseases: Histopathological Biochemical, Genetic and Molecular Bases, Vol. 2. Eukaryotes. K. Kohmoto, U. S. Singh, and R. P. Singh, eds. Pergamon, Oxford.

Kunau, W.-H., Bühne, S., de la Garza, M., Kionka, C., Mateblowski, M., Schultz-Borchard, U., and Thieringer, R. 1988. Comparative enzymology of $\beta$-oxidation. Biochem. Soc. Trans. 18:418-420.

Kusaba, M., and Tsuge, T. 1994. Nuclear ribosomal DNA variation and pathogenic specialization in Alternaria fungi known to produce hostspecific toxins. Appl. Environ. Microbiol. 60:3055-3062.

Kusaba, M., and Tsuge, T. 1995. Phylogeny of Alternaria fungi known to produce host-specific toxins on the basis of variation in internal transcribed spacers of ribosomal DNA. Curr. Genet. 28:491-498.

Kusaba, M., and Tsuge, T. 1997. Mitochondrial DNA variation in hostspecific toxin-producing pathogens in the genus Alternaria. Ann. Phytopathol. Soc. Jpn. 63:463-469.

Laughon, A., and Gesteland, R. F. 1984. Primary structure of the Saccharomyces cerevisiae GAL4 gene. Mol. Cell. Biol. 4:260-267.

Leach, J., Tegtmeier, K. J., Daly, J. M., and Yoder, O. C. 1982. Dominance at the Tox 1 locus controlling T-toxin production by Cochliobolus heterostrophus. Physiol. Plant Pathol. 21:327-333.

Lu, S., Lyngholm, L., Yang, G., Bronson, C., Yoder, O. C., and Turgeon, B. G. 1994. Tagged mutations at the Tox1 locus of Cochliobolus heterostrophus by restriction enzyme-mediated integration. Proc. Natl. Acad. Sci. USA 91:12649-12653.

Maekawa, N., Yamamoto, M., Nishimura, S., Kohmoto, K., Kuwata, M., and Watanabe, Y. 1984. Studies on host-specific AF-toxins produced by Alternaria alternata strawberry pathotype causing Alternaria black spot of strawberry. I. Production of host-specific toxins and their biological activity. Ann. Phytopathol. Soc. Jpn. 50:600-609.

Masunaka, A., Tanaka, A., Tsuge, T., Peever, T. L., Timmer, L. W., Yamamoto, M., Yamamoto, H., and Akimitsu, K. 2000. Distribution and characterization of $A K T$ homologs in the tangerine pathotype of $A l$ ternaria alternata. Phytopathology 90:762-768.

Müller-Newen, G., and Stoffel, W. 1993. Site-directed mutagenesis of putative active-site amino acid residues of 3,2-trans-enoyl-CoA isomerase, conserved within the low-homology isomerase/hydratase enzyme family. Biochemistry 32:11405-11412.

Nakashima, T., Ueno, T., Fukami, H., Taga, T., Masuda, H., Osaki, K. Otani, H., Kohmoto, K., and Nishimura, S. 1985. Isolation and structures of AK-toxin I and II, host-specific phytotoxic metabolites produced by Alternaria alternata Japanese pear pathotype. Agric. Biol. Chem. 49:807-815.

Nakatsuka, S., Feng, B.-N., Goto, T., Tsuge, T., and Nishimura, S. 1990. Biosynthetic origin of $(8 R, 9 S)-9,10$-epoxy-8-hydroxy-9-methyl-deca$(2 E, 4 Z, 6 E)$-trienoic acid, a precursor of AK-toxins produced by Alternaria alternata Japanese pear pathotype. Phytochemistry 29:1529-1531.

Nakatsuka, S., Ueda, K., Goto, T., Yamamoto, M., Nishimura, S., and Kohmoto, K. 1986. Structure of AF-toxin II, one of the host-specific toxins produced by Alternaria alternata strawberry pathotype. Tetrahedron Lett. 27:2753-2756.

Nelson, R. R., and Ullstrup, A. J. 1961. The inheritance of pathogenicity in Cochliobolus carbonum. Phytopathology 51:1-2.

Nishimura, S. 1980. Host-specific toxins from Alternaria alternata: problems and prospects. Proc. Japan Acad. (Ser. B) 56:362-366.

Nishimura, S., and Kohmoto, K. 1983. Host-specific toxins and chemical structures from Alternaria species. Annu. Rev. Phytopathol. 21:87-116.

Osumi, T., Ishii, N., Hijikata, M., Kamijo, K., Ozasa, H., Furuta, S., Miyazawa, S., Kondo, K., Inoue, K., Kagamiyama, H., and Hashimoto, T. 1985. Molecular cloning and nucleotide sequence of the cDNA for rat peroxisomal enoyl-CoA: Hydratase-3-hydroxyacyl-CoA dehydrogenase bifunctional enzyme. J. Biol. Chem. 260:8905-8910.

Otani, H., Kohmoto, K., Nishimura, S., Nakashima, T., Ueno, T., and Fukami, H. 1985. Biological activities of AK-toxins I and II, hostspecific toxins from Alternaria alternata Japanese pear pathotype. Ann. Phytopathol. Soc. Jpn. 51:285-293.

Panaccione, D. G., Scott-Craig, J. S., Pacard, J. A., and Walton, J. D.
1992. A cyclic peptide synthetase gene required for pathogenicity of the fungus Cochliobolus carbonum on maize. Proc. Natl. Acad. Sci. USA 89:6590-6594.

Pegg, K.G. 1966. Studies of a strain of Alternaria citri Pierce, the causal agent of brown spot of emperor mandarin (Citrus reticulata). Queensland J. Agric. Anim. Sci. 23:15-28.

Pitkin, J. W., Panaccione, D. G., and Walton, J. D. 1996. A putative cyclic peptide efflux pump encoded by the TOXA gene of the plant-pathogenic fungus Cochliobolus carbonum. Microbiology 142:1557-1565.

Rotem, J. 1994. The Genus Alternaria: Biology, Epidemiology, and Pathogenicity. The American Phytopathological Society, St. Paul, MN.

Rottensteiner, H., Kal, A. J., Filipits, M., Binder, M., Hamilton, B., Tabak, H. F., and Ruis, H. 1996. Pip2p: A transcriptional regulator of peroxisome proliferation in the yeast Saccharomyces cerevisiae. EMBO J. 15:2924-2934.

Scheffer, R. P., and Livingston, R. S. 1984. Host-selective toxins and their role in plant diseases. Science 223:17-21.

Scheffer, R. P., Nelson, R. R., and Ullstrup, A. J. 1967. Inheritance of toxin production and pathogenicity in Cochliobolus carbonum and Cochliobolus victoriae. Phytopathology 57:1288-1291.

Scott-Craig, J. S., Panaccione, D. G., Pocard, J. A., and Walton, J. D. 1992. The multifunctional cyclic peptide synthetase catalyzing HC-toxin production in the filamentous fungus Cochliobolus carbonum is encoded by a $15.7 \mathrm{~kb}$ open reading frame. J. Biol. Chem. 67:26044-26049.

Shiotani, H., and Tsuge, T. 1995. Efficient gene targeting in the filamentous fungus Alternaria alternata. Mol. Gen. Genet. 248:142-150.

Taga, M., and Murata, M. 1994. Visualization of mitotic chromosomes in filamentous fungi by fluorescence staining and fluorescence in situ hybridization. Chromosoma 103:408-413.

Tanaka, S. 1933. Studies on black spot disease of Japanese pear (Pyrus serotina Rehd.). Mem. Coll. Agric. Kyoto Imp. Univ. 28:1-31.

Tanaka, A., Shiotani, H., Yamamoto, M., and Tsuge, T. 1999. Insertional mutagenesis and cloning of the genes required for biosynthesis of the host-specific AK-toxin in the Japanese pear pathotype of Alternaria alternata. Mol. Plant-Microbe Interact.12:691-702.

Thompson, J. D., Higgins, D. G., and Gibson, T. J. 1994. CLUSTAL W: Improving the sensitivity of progressive multiple sequence alignment through sequence weighting, positions-specific gap penalties and weight matrix choice. Nucleic Acids Res. 22:4673-4680.

Todd, R. B., and Andrianopoulos, A. 1997. Evolution of a fungal regulatory gene family: The $\mathrm{Zn}(\mathrm{II}) 2 \mathrm{Cys} 6$ binuclear cluster DNA binding motif. Fungal Genet. Biol. 21:388-405.

Tsuge, T., Nishimura, S., and Kobayashi, H. 1990. Efficient integrative transformation of the phytopathogenic fungus Alternaria alternata mediated by the repetitive rDNA sequences. Gene 90:207-214.

Tzeng, T.-W., Lyngholm, L. K., Ford, C. F., and Bronson, C. R. 1992. A restriction fragment length polymorphism map and electrophoretic karyotype of the fungal maize pathogen Cochliobolus heterostrophus. Genetics 130:81-96.

Walton, J. D. 1996. Host-selective toxins: agents of compatibility. Plant Cell 8:1723-1733.

Walton, J. D., Ahn, J.-H., Pitkin, J. W., Cheng, Y.-Q., Nikolskaya, A. N., Ransom, R., and Wegener, S. 1998. Enzymology, molecular genetics, and regulation of biosynthesis of the host-selective toxin HC-toxin. Pages 25-34 in: Molecular Genetics of Host-Specific Toxins in Plant Disease. K. Kohmoto and O. C. Yoder, eds. Kluwer Academic Publishers, Dordrecht, The Netherlands.

Woloshuk, C. P., Fount, K. R., Brewer, J. F., Bhatnagar, D., Cleaveland, T. E., and Payne, G. A. 1994. Molecular characterization of aflR, a regulatory locus for aflatoxin biosynthesis. Appl. Environ. Microbiol. 60:2408-2414

Yang, G., Rose, M. S., Turgeon, B. G., and Yoder, O. C. 1996. A polyketide synthase is required for fungal virulence and production of the polyketide T-toxin. Plant Cell 8:2139-2150.

Yoder, O. C. 1980. Toxins in pathogenesis. Annu. Rev. Phytopathol. 18:103-129.

Yoder, O. C. 1998. A mechanistic view of the fungal/plant interaction based on host-specific toxin studies. Pages 3-15 in: Molecular Genetics of Host-Specific Toxins in Plant Disease. K. Kohmoto and O. C. Yoder, eds. Kluwer Academic Publishers, Dordrecht, The Netherlands.

Yu, J.-H., Butchko, R. A. E., Fernandes, M., Keller, N. P., Leonard, T. J., Adams, T. H. 1996. Conservation of structure and function of the aflatoxin regulatory gene aflR from Aspergillus nidulans and A. flavus. Curr. Genet. 29:549-555. 